\title{
Exploring the Hydrogen Bond Enhanced Halogen Bond
}

\author{
Daniel A. Decato, Asia Marie S. Riel, James May, and Orion B. Berryman
}

Department of Chemistry and Biochemistry, University of Montana, Missoula, MT USA, 59812

E-mail: daniel.decato@umontana.edu

The hydrogen bond enhanced halogen bond $(\mathrm{HBeXB})$ is a newly discovered synergistic relationship between hydrogen bonds (HBs) and halogen bonds (XBs). The HBeXB represents a unique method of tuning a XB by positioning a HB donor(s) proximal to the electron-rich belt of a $\mathrm{XB}$ donor. The $\mathrm{HB}$ further polarizes the electron density of the $\mathrm{XB}$ donor, making the $\mathrm{XB}$ stronger. This relationship was simultaneously demonstrated in our supramolecular chemistry group ${ }^{1}$ and a biochemistry group ${ }^{2}$, highlighting the far-reaching and diverse impact of the HBeXB.

Our seminal investigation also demonstrated the HBeXB as a tactic to engender molecular preorganization. The preorganization effects of our bidentate system precluded our ability to isolate and quantify XB augmentation afforded by an intramolecular HB. This has motivated us to develop a model system to isolate and measure XB enhancement by an intramolecular HB for the first time. Crystal structures, solution studies, and computations of both neutral and chargeassisted $\mathrm{HBeXB}$ donors will be presented.

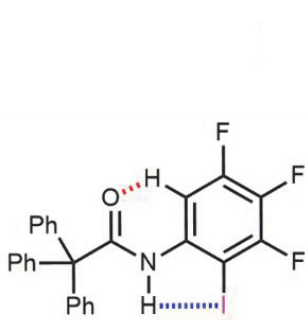

Neutral
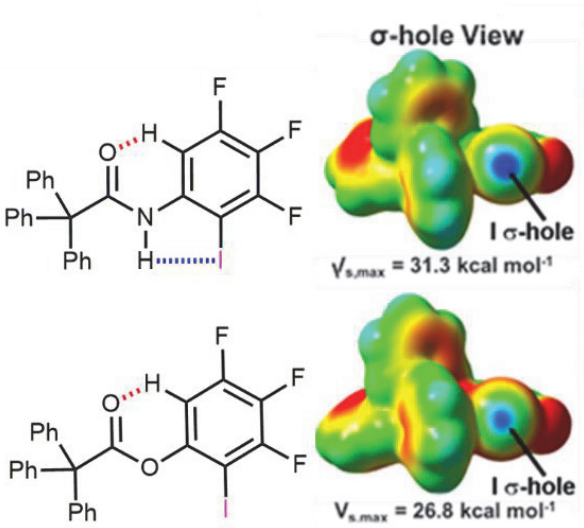
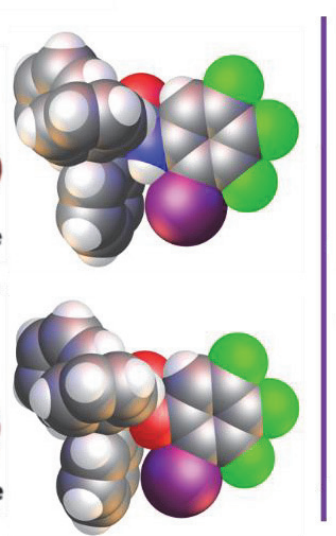

Charged

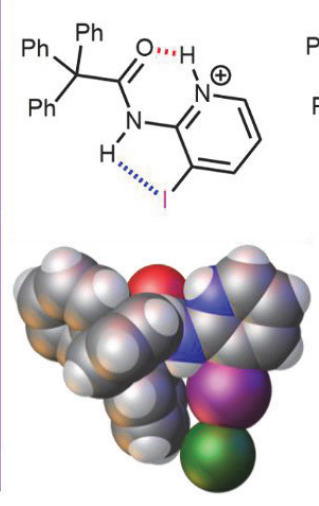<smiles>[3H]Cn1c(=O)n2c3c(c[n+](C)cc31)-c1ccccc1C2</smiles>

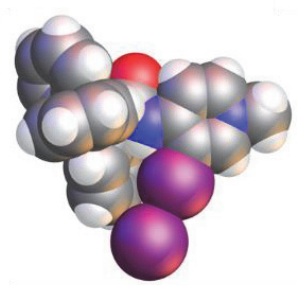

Figure 1. Crystal structures and molecular electrostatic surface potential maps (isodensity = $0.001 \mathrm{au}$ ) of neutral compounds highlighting that intramolecular HBing enhances the $\sigma$-hole (blue circle) $\mathrm{V}_{\mathrm{s} \text {, max }}$ by $4.5 \mathrm{kcal} / \mathrm{mol}$ compared to isostructural control (left). Representative examples and crystal structures of charge-assisted HBeXB compounds (right)

\section{References}

${ }^{1}$ Riel, A. M. S. $\ddagger$ Decato, D. A. ${ }^{\ddagger}$; Sun, J.; Massena, C.J.; Jessop, M.J.; and Berryman, O.B., Chem. Sci. 2018, 9, 5828-5836.

${ }^{2}$ Carlsson, A. C.; Scholfield, M. R.; Rowe, R. K.; Ford, M. C.; Alexander, A. T.; Mehl, R. A.; and Ho, P. S..; Biochemistry. 2018, 57, 4135-414. 